Carvalho, T.J.L; Ramos, J.L.; Sydow, E. O cicloturismo como fator de desenvolvimento da atividade turística nas cidades de Araguaína e Nova Olinda (TO). Anais do IX Congresso Nacional de Ecoturismo e do V Encontro Interdisciplinar de Turismo em Unidades de Conservação. Revista Brasileira de Ecoturismo, São Paulo, v.6, n.4, nov-2013, pp.63-82.

\title{
O cicloturismo como fator de desenvolvimento da atividade turística nas cidades de Araguaína e Nova Olinda (TO)
}

\author{
The Bicycle Touring as a factor of development of touristic activities in the \\ cities of Araguaína and Nova Olinda (TO, Brazil)
}

Thiago Junior Lima Carvalho, Jônatas Leite Ramos, Elisabeth Sydow

\begin{abstract}
RESUMO
O cicloturismo é uma modalidade do ecoturismo que está ganhando cada vez mais adeptos no país, por ser uma atividade de baixo impacto ambiental, já que é realizado com bicicletas. Além disso, é uma atividade de lazer que contribui para uma melhor qualidade de vida e proporciona ao ciclista um contato maior com o ambiente visitado. O objetivo deste trabalho foi verificar a possibilidade de implementação de roteiros de cicloturismo para contribuir com o desenvolvimento da atividade turística na região. Inicialmente, fez-se um levantamento bibliográfico sobre o tema em livros, revistas, internet, artigos, monografias, manuais e normas técnicas da ABNT. Posteriormente, foi-se a campo para identificar as condições das estradas, as potencialidades e a infraestrutura turística da região. Os resultados comprovaram a viabilidade dos roteiros. No entanto, os destinos finais ainda possuem infraestrutura insuficiente para receber turistas, mas a consolidação dos potenciais itinerários poderá vir a sanar a maioria das deficiências encontradas e contribuir para a geração de emprego, aumento da renda e, consequentemente, melhoria da qualidade de vida da população local.
\end{abstract}

PALAVRAS-CHAVE: Ecoturismo; Cicloturismo; Roteiros; Desenvolvimento Local.

\section{ABSTRACT}

The bicycle touring is a segment of ecotourism that is gaining more and more followers in the country, for be an activity with low environmental impact, as it is done with bicycles. Moreover, it is a leisure activity that contributes to a better quality of life and gives the rider greater contact with the environment visited. The aim of this study was investigate the possibility of implementing cycling routes to contribute to the development of tourism activity in the region. Initially, was a literature on the subject in books, magazines, internet, articles, monographs, manuals and technical standards of ABNT. Later, was a technical visit to identify road conditions, potential tourist and infrastructure of the region. The results proved the feasibility of the routes. However the final destinations still have insufficient infrastructure to receive tourists, but the consolidation of potential itineraries is likely to remedy most of the deficiencies found and contribute to job creation, increase in income, and consequently improving the quality of life of local people.

KEYWORDS: Ecotourism; Bicycle Touring; Roadmaps; Local Development. 


\section{Introdução}

O homem, desde seus primórdios e por motivos diversos, sentia necessidade de sair do seu local de origem para explorar outras regiões e descobrir novos caminhos. Por isso, o deslocamento sempre fez parte do cotidiano das pessoas bem como, para vários autores, ele é considerado como ponto inicial da atividade turística, que ajuda a incrementar a economia de diversas localidades.

Fatores aliados ao crescimento das cidades, aumento da renda e do tempo livre atuam como base de solidificação das atividades turísticas, principalmente aquelas realizadas em contado com a natureza. Entre as diversas modalidades do turismo, a que se encontra em maior expansão é o ecoturismo que é um dos segmentos da atividade turística que utiliza de maneira sustentável o patrimônio natural e cultural. Além disso, incentiva sua conservação e busca a formação de uma consciência ambiental, valorizando o espaço e consequentemente a comunidade local. $\mathrm{O}$ aumento do trânsito, do sedentarismo e da poluição aumentou a busca por uma qualidade de vida e a relação do homem com a natureza. É por isso que os profissionais de turismo estão cada vez mais preocupados com o impacto ambiental que a atividade turística pode trazer. É neste contexto que a bicicleta surge como uma solução eficiente, especialmente para o turismo sustentável.

O cicloturismo é um segmento do turismo que movimenta outras cinco modalidades: o turismo rural, o ecoturismo, turismo de aventura, turismo cultural e gastronômico. Também é uma atividade do turismo de lazer que permite o exercício físico, contato com a natureza e a experiência de conhecer detalhes de lugares que seriam imperceptíveis em outros meios de transporte. O desenvolvimento de roteiros de cicloturismo pode atuar como vetor de diversificação da economia regional, geração de emprego, valorização da herança cultural, conservação do patrimônio (histórico, ambiental e cultural), divulgação da cidade e incentivo para a permanência de turistas mesmo em baixa temporada. Podem, ainda, criar na comunidade e nos visitantes a conscientização sobre a importância da preservação ambiental, partindo do princípio "conhecer para preservar" e, também, agir como meio de fixação da população rural, evitando o processo do êxodo.

Para Cavallari (2012, p.133):

Hoje, o cicloturismo representa muito mais do que apenas uma forma eficiente e econômica de viagem. Em meio à crise climática, aos questionamentos éticos e econômicos sobre nosso atual estilo de vida, nosso métodos de produção e hábitos de consumo, diante da busca constante e mais responsável por melhor qualidade de vida, novamente a bicicleta, através do cicloturismo, apresenta seu discurso revolucionário e libertário. 


\section{Desenvolvimento do Turismo}

Para Ignarra (2003) a expansão do turismo está ligada a vários fenômenos da globalização. A evolução dos meios de transporte, especialmente o ferroviário, facilitou a locomoção do homem marcando o início das infraestruturas turísticas, tornandoa uma atividade altamente lucrativa.

O turismo é um importante impulsionador de geração de renda para as pessoas. As localidades que descobrem e trabalham seu potencial turístico são automaticamente beneficiadas em diversas áreas.
A atividade turística é entendida como um fator importante para qual- quer economia local, regional ou nacional, pois o movimento constante de novas pessoas aumenta o consumo, incrementa as necessidades de maior produção de bens, serviços e empregos e, consequentemen- te, a geração de maiores lucros, que levam o aumento de riquezas pe- la produção da terra, pela utilização de equipamentos de hospedagem e transporte e pelo consumo ou aquisição de objetos diversos, de ali- mentação e de prestação dos mais variados serviços (ALEXANDRE, 2003, p.6).

Segundo o Plano Aquarela 2020 (2009), a renda total gerada pelo turismo internacional em 2008 alcançou US $\$ 1,1$ trilhão e respondeu por $30 \%$ de todas as exportações de serviços do mundo. No Brasil a renda foi em torno de 5,8 bilhões. A marca recorde de 197 milhões de viagens internas em 2012, divulgadas pelo Ministério do Turismo, apenas demonstra o crescimento do turismo interno.

A ascensão do setor turístico, assim como sua expansão econômica no cenário global, levou a necessidade de estudar, planejar e desenvolvê-lo como fonte econômica mundial. O turismo integra diversas áreas, de forma direta ou indireta, necessitando de parcerias para o sucesso da atividade. Essas parcerias ajudam a consolidar os atrativos turísticos. Para Melgar (2001), são elas que incentivam o deslocamento das pessoas para ver, fazer, sentir ou desfrutar de sua existência. Mas antes de consolidar um atrativo é preciso identificar o seu potencial e criar metas para preservar seus bens naturais e culturais, pois o desenvolvimento turístico sem planejamento pode trazer impactos negativos.

Para Alexandre (2003), o turismo precisa ser planejado para que as necessidades e potencialidades sejam gerenciadas e transformadas em estratégias que levem à inclusão do patrimônio natural, histórico e cultural no circuito econômico, evitando seu uso predatório. Por isso, o turismo deve se desenvolver de forma sustentável, conciliando a atividade com a conservação ambiental.

Beni (2004) afirma que a melhor maneira de estudar turismo é através de segmentação, que é a decomposição da população em grupos homogêneos e traz enormes vantagens competitivas para as empresas do mercado. 
Segundo Ignarra (2003) um mercado composto por milhões de consumidores precisa se segmentar para compreender de forma mais rápida sua estrutura e suas necessidades. A segmentação se torna um recurso eficaz para planejar, estudar e satisfazer demandas diversas. Para o Ministério do Turismo (2008) "a segmentação é uma forma de organizar o turismo para fins de planejamento, gestão e mercado". Ainda segundo o autor, a segmentação do turismo não é excludente nem estática. Assim como as viagens podem ter mais de um motivo caracterizados em segmentos diferentes, um local pode ter potencialidade para mais de um segmento. Um destino que se especializa em apenas em um tipo de segmento está enfraquecendo seu mercado, perdendo divisas importantes trazidas por outros tipos de turistas.

Para Poon (2007, apud NETTO et al., 2009) a atividade turística está ficando mais flexível, segmentada, diagonalmente integrada e ambientalmente sensata. Em um planeta onde se prega constantemente um desenvolvimento econômico sustentável, a segmentação do turismo ecológico vem se transformando em um mediador da harmonização do homem com a natureza, com destaque para o Ecoturismo, um segmento amplo que possui diversas modalidades.

\section{Ecoturismo}

Segundo Bueno et al. (2011) no inicio do século XX, as teorias Fordistas, além de modificarem a indústria, modificaram também as atividades turísticas. Estas ganharam características mais padronizadas, quando começaram a comercializar pacotes turísticos que ofertavam serviços como alimentação, transporte e recreação, produzindo o modelo caracterizado como turismo de massa. O turismo de massa acabou causando desastres ambientais durante a década de 1960, comprometendo as belezas naturais de diversas regiões.

A Comissão Mundial sobre Meio Ambiente e Desenvolvimento, criada pelas Nações Unidas, define o modelo de desenvolvimento sustentável como um "desenvolvimento capaz de suprir as necessidades da geração atual, sem comprometer a capacidade de atender as necessidades das futuras gerações". É o desenvolvimento que não esgota os recursos para o futuro.

Segundo Ceballos-Lascurián (1993, apud MEDINA, 2007), o turismo se destaca neste contexto por gerar riqueza através do uso dos recursos naturais aliados às premissas da sustentabilidade. Então, no confronto dos dois modelos citados, o turismo sustentável se destaca como solução para os problemas ambientais enfrentados atualmente.

Os movimentos ambientalistas fizeram o turismo passar por um processo de mudança cultural, tornando-se mais conservacionista. Eventos como a Conferência de Estocolmo, em 1972, e a Rio 92 ampliaram os debates sobre o desenvolvimento sustentável, fazendo com que os gestores aprendessem a conciliar a promoção de um destino turístico com a conservação.

Segundo Fonseca (2009), a promoção de um atrativo serve para atrair e ampli- 
ar o fluxo de turistas, já a conservação serve para controlar esse fluxo, visando a preservação do meio ambiente sem atrapalhar o desenvolvimento da comunidade local, incentivando suas tradições e manifestações culturais, transformando-as em atrativos para os turistas.

Foi para ajudar a atividade turística nesse processo de preservação que surgiu um novo segmento no setor: o Ecoturismo. As primeiras manifestações de práticas ecoturísticas foram motivadas por uma procura de mudança na qualidade de vida, fuga do estresse e da agitação dos grandes centros urbanos. Bueno et al. (2011), considera o Ecoturismo como uma modalidade do Turismo que busca a conservação ambiental. Segundo definição do Instituto Brasileiro de Turismo - EMBRATUR:

O Ecoturismo é um segmento da atividade turística que utiliza, de forma sustentável, o patrimônio natural e cultural, incentiva sua conservação e busca a formação de uma consciência ambientalista através da interpretação do ambiente, promovendo o bem-estar das populações envolvidas.

Segundo o Programa das Nações Unidas para o Meio-Ambiente - PNUMA (apud BUENO, et al., 2011), o Ecoturismo define-se pelo contado com a natureza, provocando em seu participante um comprometimento com conservação e preservação, baseados no tripé da sustentabilidade, conservação e interpretação. Para o Ministério do Turismo, o Ecoturismo é uma importante ferramenta de conservação da natureza e assume um papel de difusor das informações ambientais, principalmente através da ligação entre preservação e geração de renda, incomum em outras atividades econômicas, gerando assim uma corrente educacional preservacionista demonstrando-se eficiente na solução de problemas conhecidos e não solucionados por outras atividades.

De acordo com Mendonça e Neiman (2005) para conservar a natureza é necessário ir além da criação de normas técnicas e leis. É preciso trabalhar as pessoas, despertando sua consciência ecológica e incentivando sua relação com o ambiente natural. A educação ambiental nas visitas à natureza é a base inicial para a formação de uma sociedade sustentável e deve, além do desenvolvimento com a comunidade local, trazer uma experiência que possa enriquecer e conscientizar. Neiman (2008) afirma que o processo de educação ambiental, aliando teoria à prática, vem como uma tentativa de resgatar valores, trazendo uma nova relação entre o homem e a natureza. Ainda para o autor, o ecoturismo, no Brasil, é antagônico, pois para os especialistas ele é "a melhor alternativa para conciliar conservação, Educação Ambiental e benefícios às comunidades receptivas", mas são raros os roteiros que se apoiam nesse tripé, predominando o "quanto mais, melhor".

O Ecoturismo tem se mostrado um importante campo de atuação no desenvolvimento da educação ambiental, fundamentada na própria Política Nacional do Turismo, que a define como base para promoção entre a comunidade e os turistas. A visita a lugares onde a natureza demonstra sua pujança pode ser direcionada a mudanças 
nas percepções conservacionistas. O afeto com a natureza e com a cultura local possibilita o desenvolvimento de uma visão lúdica de apropriação, ampliando sua interpretação sobre o meio ambiente. Porém, é necessário que os moradores percebam a importância da conservação, pois uma sociedade consciente do seu papel e sua relação com o meio ambiente torna-se mais preparada para cobrar dos turistas o mesmo respeito dado pela comunidade.

A atividade ecoturística pode proporcionar novas oportunidades de trabalho e renda para a população local através da interação entre os turistas e a comunidade, agregando valor ao produto turístico sem esquecer a importância da associação entre os poderes públicos, privado e a comunidade para o desenvolvimento do ecoturismo. A inclusão da comunidade, seja como forma de desenvolver o produto turístico ou como forma de aumentar os atores na tomada de decisões, criam resoluções democráticas que geram apoio para a proteção ambiental. É nesse contexto que há uma ligação entre o turismo convencional e o turismo de base comunitária, que tem como meta a inclusão da comunidade como tomadora de decisões sobre a atividade turística. Surge então um novo modelo que engloba as duas premissas, chamado de "ecoturismo de base comunitária".

Algumas pessoas confundem o Ecoturismo com o Turismo de Aventura. O Turismo de Aventura é uma modalidade que engloba atividades esportivas de caráter recreativo, que podem ocorrer em diversos espaços (natural, construído, urbano, rural). Já o Ecoturismo é mais abrangente e pressupõe atividades em espaços exclusivamente naturais, que promovem a reflexão e integração entre o homem e ambiente. Entre essas atividades se destaca o Cicloturismo. Para Bueno, et al. (2011), o Cicloturismo é considerada uma modalidade do Ecoturismo, pois é um lazer que se compromete com a conservação de áreas naturais e incentiva um relacionamento com as comunidades visitadas.

\section{Cicloturismo}

Segundo Roldan (2000) os primeiros relatos sobre o surgimento da bicicleta ocorreram em 1817 quando o Barão alemão Karl Drais Von Samerbroon (1785-1851) desenvolveu um veículo de duas rodas feito completamente de madeira, que o ajudaria a passear mais rápido pelos jardins reais. O veículo era impulsionado empurrando os pés contra o chão, causando certo desconforto nos pés. Os pedais apareceram pela primeira vez em 1865 na França, na invenção conhecida como "velocípede". Eles eram incorporados na roda dianteira. Cavallari (2012, p. 133) cita que o velocípede "logo se transformou em um veículo de transporte, eficiente e econômico, para a crescente classe trabalhadora urbana na Inglaterra, da época da Revolução Industrial'.

Roldan (2000) afirma que a primeira máquina a ser chamada de bicicleta (termo que significa duas rodas) surgiu em 1870. Com o avanço da metalurgia, que passou a fornecer metais resistentes para a fabricação de peças mais compactas e leves, a bicicleta deixou de ser feita em madeira. A roda dianteira do novo modelo era maior que a roda traseira, pois os construtores descobriram que quanto maior fosse 
essa roda, maior era a distância percorrida com um giro dos pedais. Porém, o principal problema deste modelo era o centro de gravidade na dianteira, que facilitava o giro em torno do seu eixo, fazendo com que seu condutor caísse de cabeça no chão. Para minimizar os acidentes, foram desenvolvidas bicicletas com roda traseira grande e roda pequena na frente, impedindo o giro em torno do eixo. A roda com pneu foi introduzida pelo veterinário irlandês Dunlop, substituindo as rodas de metais e madeira, deixando as pedaladas mais confortáveis.

Segundo Cavallari (2012) com a melhoria dos métodos de fabricação, as bicicletas foram ficando cada vez mais baratas e populares. Tanto que em 1878 foi fundado na Inglaterra o Bicycle Touring Club, mais tarde rebatizado de Cyclist's Touring Club (CTC). Essa entidade inspirou o patrono do ciclismo francês Paul de Vivie (19531930) a iniciar em 1881, o que viria a se tornar mais tarde a Féderátion Française de Cyclotourisme (Federação Francesa de Cicloturismo), criando assim o termo cicloturismo, que mais tarde foi adotado em boa parte do mundo.

A possibilidade de usar a bicicleta como meio de transporte em viagens, provocou a união entre o turismo e o ciclismo. Para Roldan (2000) a atividade une o prazer da realização de uma viagem com a paixão pelo ciclismo.

A Associação Brasileira de Normas Técnicas - ABNT (2007) define o cicloturismo como uma atividade turística que tem como elemento principal a realização de roteiros de bicicleta.

Segundo Roldan (2000, p.24)

[...] entendemos o cicloturismo como todo o tipo de viagem com um dia ou mais de duração, que tenha como objetivo conhecer lugares e praticar turismo, utilizando a bicicleta como meio de locomoção, diferenciando de outras atividades competitivas por suas maiores dimensões espaciais cronológicas e seu planejamento prévio.

Já para Schetino (apud FONSECA, 2009) além de ter a bicicleta como principal meio de transporte, o cicloturismo se diferencia do turismo esportivo porque o segundo tem como foco o esporte e o turismo permanece em segundo plano.

Segundo o Manual de Incentivo e Orientação para Municípios Brasileiros: Circuitos de Cicloturismo, desenvolvido pela Associação dos Ciclousuários de Florianópolis (ViaCiclo), o cicloturismo é um segmento do turismo que movimenta outras cinco modalidades: o turismo rural, o ecoturismo, turismo de aventura, turismo cultural e gastronômico. E que todos os municípios brasileiros têm potencial para atender pelo menos duas destas modalidades.

Para Cavallari (2012) cicloturismo não exige uso de grandes equipamentos e necessita da estrutura social disponível na região para realizar seu percurso, como meios de hospedagem, bares, padarias, restaurantes e comércio em geral. Ele ainda sugere que para o cicloturismo a bike precisa ter componentes leves para vencer obs- 
táculos com segurança e rapidez, economizando a energia de quem está pedalando.

Apesar de existir há bastante tempo na Europa, o cicloturismo ainda é uma atividade recente no Brasil. Segundo o Manual Circuitos de Cicloturismo, o primeiro circuito oficial brasileiro foi o Circuito Vale Europeu (na região do Vale do Itajaí) em 2006, e que se transformou em uma referência no cenário turístico nacional, chegando a registrar no ano de 2010 cerca de 4.000 visitações. Há, também, o Clube de Cicloturismo do Brasil, criada em 2001, que difunde e incentiva a prática da atividade no país e possibilitar a troca de informações entre os cicloturistas.

Ainda de acordo com o manual, o cicloturista viaja para ficar em contato com a natureza, conhecer zonas rurais e se relacionar com a comunidade local. Ele vive intensamente o trajeto e dá tanta ou maior importância ao percurso quanto ao destino final.

Entender o perfil deste turista com características específicas é essencial para divulgar melhor qualquer roteiro cicloturístico. A tabela a seguir demonstra o resultado de uma pesquisa realizada com 302 cicloturistas praticantes, durante o período de março a abril de 2008 no site do Clube de Cicloturismo do Brasil sob a coordenação de Andressa Paupitz.

Tabela 1: perfil do cicloturista brasileiro.

Table 1: Profile of the Brazilian bicycle tourist.

\begin{tabular}{|l|l|}
\hline $85 \%$ & Dos participantes são do sexo masculino \\
\hline $52 \%$ & Preferem realizar viagens com amigos ou em casal \\
\hline $71 \%$ & Estão numa faixa etária entre 26 e 45 anos \\
\hline $53 \%$ & São casados \\
\hline $52 \%$ & Preferem pedalar distancias entre 50 e 100 quilômetros \\
\hline $53 \%$ & Preferem pedalar em pista de terra \\
\hline $35 \%$ & Tem como motivação o contato com a natureza e o ambiente \\
\hline $44 \%$ & Tem como motivação a aventura da viagem \\
\hline
\end{tabular}

Fonte: PAUPITZ (2008). Souce: Paupitz (2008)

Para Cavallari (2012), o cicloturista viaja em busca da filosofia da experiência ao ar livre,entrando em contato com a natureza e com a população local. Ele precisa conhecer e seguir códigos de ética, respeitando principalmente as comunidades. $\mathrm{O}$ autor recomenda algumas iniciativas como reconhecer e respeitar a ordem social, política e econômica local;respeitar os limites territoriais estabelecidos e estabelecer uma passagem minimamente impactante.

Quanto aos impactos ambientais ele cita algumas regras que podem ser adotadas pelos cicloturistas e condutores para minimizá-los, como escolher terrenos mais duráveis 
para pedalar (como rochas e areia); não pedalar de forma desnecessariamente agressiva; evitar danificar a vegetação com a bicicleta; evitar cruzar cursos de água (especialmente córregos rasos, nascentes e fios de água), pois a bicicleta pode causar assoreamento e contaminar a água com óleo ou afins; evitar abrir atalhos; nunca deixar sujeira para trás e evitar fazer fogueiras.

É essencial, também, que um roteiro de cicloturismo obedeça regras e normas de segurança para minimizar situações de risco. Há um protocolo básico de segurança, que pode ser aplicado em qualquer trilha, roteiro de cicloturismo ou cicloexpedição, como: evitar pedalar sozinho e à noite; manter vacinas em dia; usar roupas e calçados adequados ao roteiro e ao clima; não pedalar sobre calçadas e demais locais reservados exclusivamente para pedestres; não pedalar em vias de mão única na contramão; lembrar de sinalizar mudanças na direção; manter-se hidratado; levar lanterna de cabeça com pilhas extras; levar lanche de trilha ou refeição; ter sempre um mapa impresso do roteiro em mãos para evitar falhas de aparelhos eletrônicos.

Quanto ao roteiro, é importante estudá-lo previamente adquirindo o máximo de informações; analisar sua viabilidade e adquirir dados sobre cada um dos participantes e contar com o auxílio de carros de apoio.

Em relação ao direito de prioridade durante um roteiro de Cicloturismo é importante saber que o Código Nacional de Trânsito indica a bicicleta como tendo a preferencial sobre os demais veículos.

Art. 58 - Nas vias urbanas e nas rurais de pista dupla, a circulação de bicicletas deverá ocorrer, quando não houver ciclovia, ciclofaixa ou acostamento, ou quando não for possível a utilização destes, nos bordos da pista de rolamento, no mesmo sentido de circulação regulamentado pela via, com preferência sobre os veículos automotores.

\section{Normas da ABNT para cicloturismo}

Para garantir que um roteiro de cicloturismo seja feito com segurança e qualidade, a ABNT - Associação Brasileira de Normas Técnicas em parceria com o Ministério do Turismo criou a Norma NBR 15509-1 (2007) específica para a operação de guias e condutores em cicloturismo.Essa Norma é uma extensão das Normas NBR 15285, NBR 15286 e NBR 15331 quem tratam do Turismo de Aventura.

De acordo com a Norma, o condutor precisa ter noções de mecânica de bicicleta para dar apoio em situações adversas; técnicas de dirigibilidade de bicicleta e posicionamento de corpo nas diferentes situações de progressão; ergonomia da bicicleta e regulagem de selim e guidão para diferentes pessoas; direção defensiva e aptidão física condizente com o percurso.

O uso de veículos de apoio também é essencial para garantir a segurança do roteiro. A Norma sugere a quantidade de condutores e clientes em operações com 0 
auxílio de veículos de apoio, conforme a tabela 2.

Tabela 2: exemplo da relação de quantidade de condutores e clientes em operações com veículo de apoio.

Table 2: example of the relationship of the number of guides and customers in operations with support vehicle.

\begin{tabular}{|c|c|}
\hline \multicolumn{2}{|c|}{ Operação com veículo de apoio } \\
\hline Quantidade de clientes & Quantidade mínima de condutores \\
\hline 1 a 5 & 1 \\
\hline 6 a 10 & 2 \\
\hline 11 a 20 & 3 \\
\hline 21 a 30 & 4 \\
\hline
\end{tabular}

Fonte: ABNT NBR 15509-01 (2007). Source: ABNT NBR 15509-01 (2007).

Para operações sem veículo de apoio, a Norma sugere um condutor para cada conjunto de seis clientes, conforme tabela 3.

Tabela 3: exemplo da relação de quantidade de condutores e clientes em operações com veículo de apoio. Table 23 example of the relationship of the number of guides and customers in operations without support vehicle.

\begin{tabular}{|c|c|}
\hline \multicolumn{2}{|c|}{ Operação sem veículo de apoio } \\
\hline Quantidade de clientes & Quantidade mínima de condutores \\
\hline 1 a 6 & 1 \\
\hline 7 a 12 & 2 \\
\hline 13 a 18 & 3 \\
\hline 19 a 24 & 4 \\
\hline
\end{tabular}

Fonte: ABNT NBR 15509-01 (2007). Source: ABNT NBR 15509-01 (2007).

A Norma sugere que alguns equipamentos sejam disponibilizados, tais como: estojo de primeiros-socorros; lanterna; relógio; cabos de câmbio; óleo lubrificante; adaptador de válvula para câmaras de ar; chave de válvula de câmara; alicate de corte; aparelho de comunicação para o veículo de apoio, entre outros.

O conjunto de ferramentas básico da operação deve conter jogo de chaves Allen; jogo de chaves de boca; bomba de ar; câmara de ar; chaves de fenda; chaves Philips; alicate de bico; chave de corrente e kit reparo de câmara.

Para o cliente, a organização deve dispor e assegurar bicicleta adequada ao 
tipo de percurso; recipiente para água (como caramanhola, cantil e mochila de hidratação); vestimenta e calçado fechado adequado,capacete de ciclismo, luvas de ciclismo e óculos para proteção.

A organização ainda deve ser responsável pela inspeção periódica e manutenção preventiva desses equipamentos. O responsável pela operação deve avaliar as habilidades do cliente em um percurso teste ou num trecho inicial do próprio percurso. O objetivo dessa avaliação é verificar sua aptidão física para seguir o roteiro. Ele ainda tem o dever de esclarecer algumas informações antes da partida, como o tempo de duração, pontos e horários para alimentação; descrição das características do local; tipo de percurso; procedimentos de mínimo impacto ambiental; descrição dos cuidados com a segurança; verificação e exigência de vestuário apropriado para a atividade; se o produto inclui seguro, entre outros.

\section{Roteiros}

\section{Roteiros Araguaína/Cachoeira do Jenipapo}

A cidade de Araguaína está localizada ao norte do estado do Tocantins próxima a divisa dos estados do Pará e Maranhão e a $350 \mathrm{~km}$ da capital Palmas. Segundo dados do Instituto Brasileiro de Geografia e Estatística - IBGE (Censo 2010) a cidade conta com a segunda maior população do Estado com cerca de 150.000 habitantes. O município também é reconhecido como capital econômica do estado, com destaque na área de serviços (movendo cerca de 50\% do Produto Interno Bruto) e para a zona rural com predominância da pecuária de corte além de ser considerado um forte polo econômico regional.

Ainda, segundo o IBGE, a região do município é caracterizada como área de transição de Cerrado para Amazônia contendo características destes dois biomas. O clima pode ser definido como tropical úmido com temperatura média de 30 . Com paisagens repletas de córregos, riachos e rios é denominada pela Agência de Desenvolvimento Turístico - ADTUR como "vale dos grandes rios", por estar situada entres os rios Araguaia e Tocantins.

O roteiro sugerido é em uma estrada de terra que liga a cidade de Araguaína até a Cachoeira do Jenipapo na região do município de Babaçulândia. A estrada entrou em desuso após a pavimentação da TO-423 que liga a TO-222, transformando-o num trajeto mais rápido e seguro para veículos automotores. $O$ roteiro tem início no Bairro Jardim das Flores, com aproximadamente 42 quilômetros até a Cachoeira do Jenipapo, e pode ser dividida em três etapas (Figura 1). 


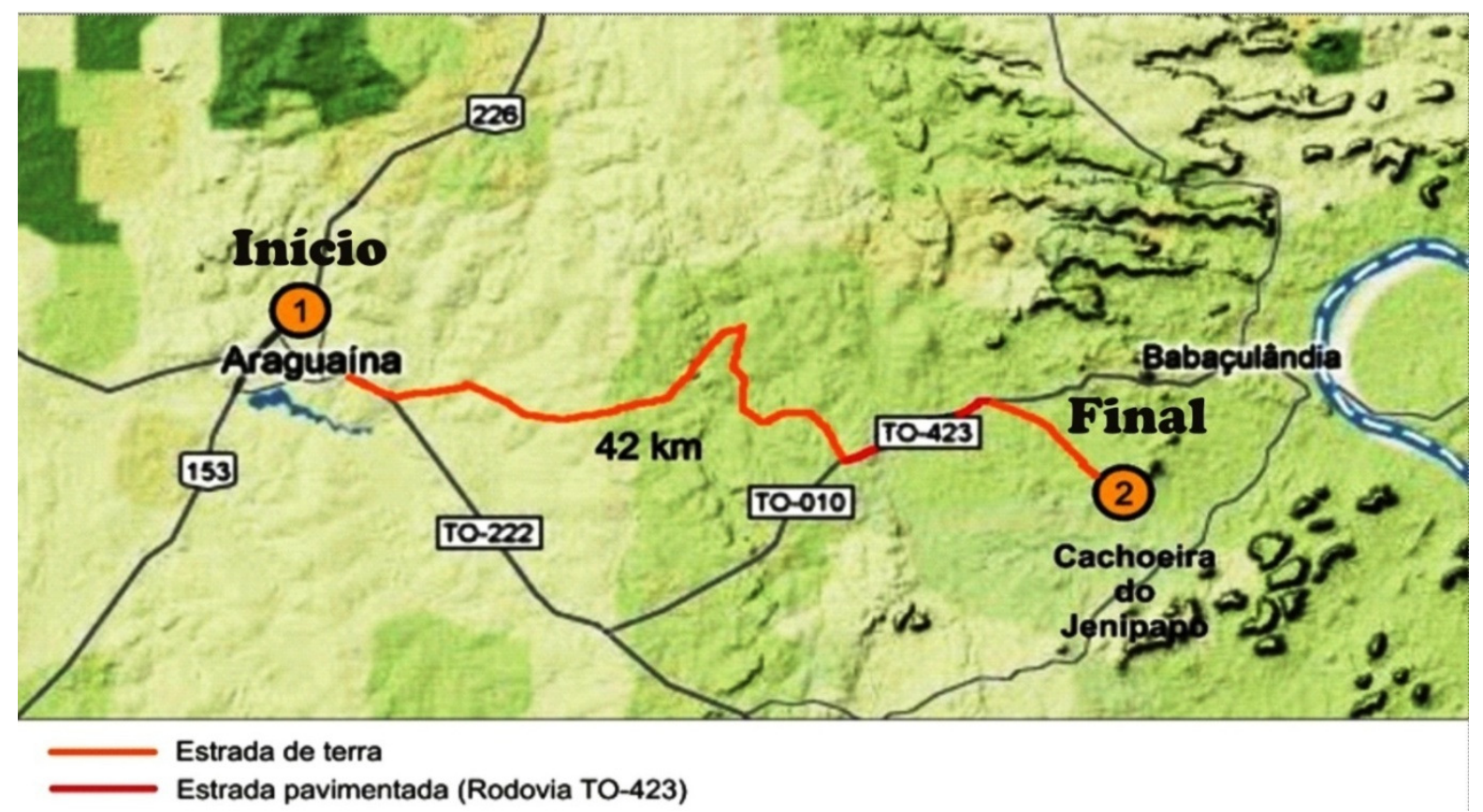

Figura 1: mapa do roteiro araguaína/cachoeira do jenipapo.

Figura 1: Maps of tour araguaína/cachoeira do jenipapo.

Fonte: Google Mapas (2013). Alterado por Thiago Carvalho.

Source: Google Maps (2013). Modified by Thiago Carvalho.

A primeira etapa liga a cidade de Araguaína até a TO-423 com aproximadamente 32 quilômetros de estrada de terra, a segunda parte é o trecho asfaltado de aproximadamente $7 \mathrm{~km}$ de extensão sobre a TO-423 e a última parte é o trajeto de aproximadamente $3 \mathrm{~km}$ em estrada de terra (Figura 2). O tempo médio do percurso é de $2 \mathrm{~h}$, pedalando na velocidade média de $25 \mathrm{~km} / \mathrm{h}$. É um roteiro que não exige pernoite, pois é possível ir e voltar no mesmo dia.

As boas condições das estradas, aliadas ao relevo quase plano da região, exigem do ciclista menos experiência e qualidade técnica. A rodovia TO-423 está em ótimo estado de conservação e as larguras das estradas possibilitam a presença de mais grupos com menos impacto ao meio ambiente.

O caminho apresenta diversas características geográficas e culturais da região, com a presença de grandes quantidades de riachos que cortam a estrada. O local é cercado de áreas arborizadas e bem conservadas que permitem o inicio do lazer antes da chegada ao ponto final. As fazendas de criação de gado e a agricultura de base familiar também estão presentes principalmente no inicio e na última parte do trajeto. $O$ roteiro cruza com a Ferrovia Norte-Sul e também há uma grande área preservada com vegetação típica da transição entre cerrado e Amazônia, que descrevem o bioma regional. 


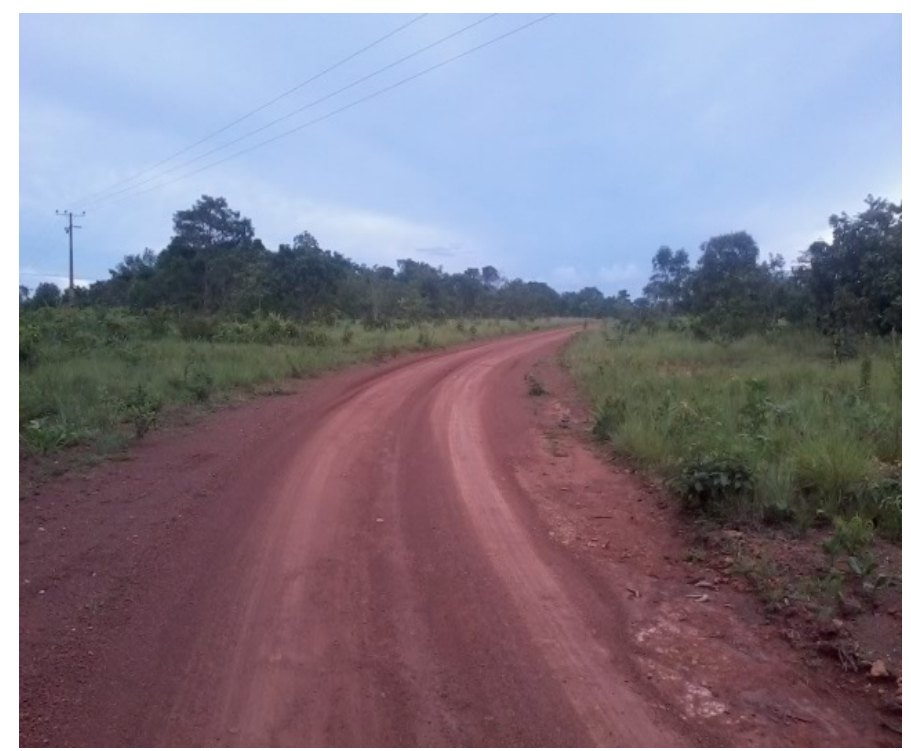

Figura 2: trecho da estrada de terra que liga Araguaína a Cachoeira do Jenipapo. Figure 2: stretch of dirt road that connects the Araguaína to Waterfall of Jenipapo.

Foto: Autores (2013). Photo: Authors (2013).

A Cachoeira do Jenipapo (Figura 3), o ponto final, é um dos principais atrativos do município de Babaçulândia que está localizada cerca de $47 \mathrm{~km}$ de Araguaína seguindo o trajeto TO-222 e TO-423. A cachoeira tem cerca de 8 metros de altura, dividida em três quedas. O local ainda conta com uma pequena infraestrutura com restaurante e bar, banheiros, área segura para banho e trilha indicativa para caminhada até o local da queda de água.

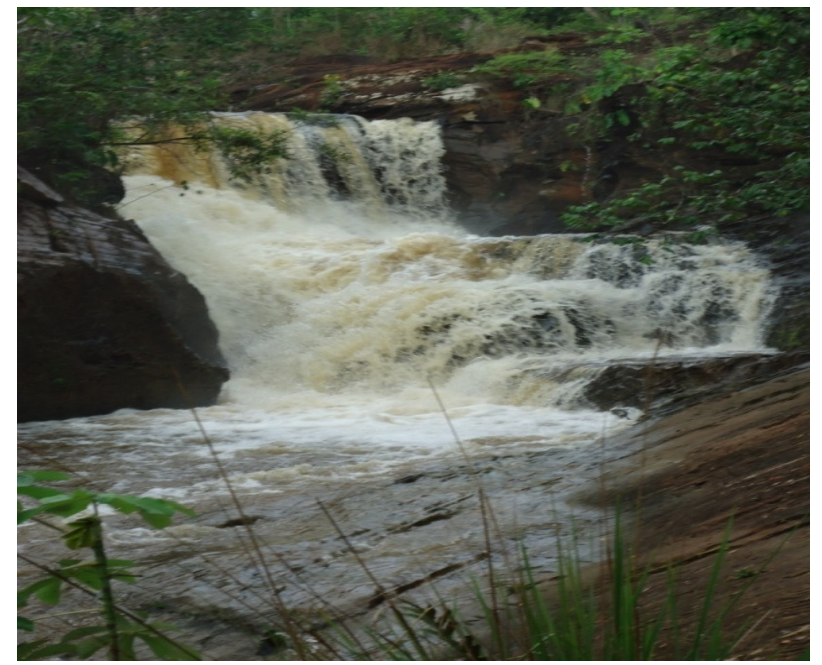

Figura 3: Cachoeira do Jenipapo localizada na região de Babaçulândia Figure 3: Waterfall of Jenipapo localized in the Babaçulândia reigions.

Foto: Autores (2013). Photo: Authors (2013). 


\section{Roteiro Nova Olinda/Palmeirante}

Nova Olinda está localizada na microrregião de Araguaína. De acordo comdados do IBGE (2010), a população local é de 10.686 habitantes e sua área é de $1.566 \mathrm{~km}^{2}$. Boa parte da renda do município vem da agropecuária e de algumas indústrias locais.

O município de Palmeirante também está localizado na Mesorregião Ocidental do Tocantins e na Microrregião de Araguaína, em uma área de $2.641 \mathrm{~km}^{2}$, nas margens do Rio Tocantins. Segundo os dados do IBGE (Censo 2010) sua população é de 4.954 habitantes e, boa parte da sua renda vem da agropecuária e da pesca. O povoado de Palmeirante foi durante muito tempo conhecido como Olho Grande, pois segundo relatos dos moradores mais velhos do local, alguns pescadores ao olharem para o rio à noite, viram uma grande cabeça de um bicho desconhecido que possuía apenas um olho grande no meio da testa. Mas entre os mais jovens, corre a notícia que o lugar teria recebido o nome de Olho Grande por que ali viviam pessoas muito invejosas.

Os dois municípios têm festas de tradições religiosas. Em Palmeirante, do dia 10 ao dia 19 de março e na segunda quinzena de setembro, se comemora o festejo de Nossa Senhora de Nazaré. Já em Nova Olinda, no dia 29 de junho, é celebrada solenemente a festa de São Pedro Apóstolo, o padroeiro da cidade. As cidades também contam com uma infraestrutura básica para receberem turistas como pousadas, hotéis, restaurantes, hospitais, postos de saúde, farmácias, entre outros. A criação de um roteiro cicloturístico irá incentivar a atividade turística nos municípios e ajudar a incrementar a renda da região.

O roteiro exige um preparo físico maior, já que é um percurso mais extenso de 80 km (Figura 4). O ponto de encontro sugerido para a partida desse roteiro é a Praça da Igreja Matriz de São Pedro Apóstolo, um ponto de referência na cidade de Nova Olinda. O cicloturista irá pedalar aproximadamente $2 \mathrm{~km}$ dentro da cidade até entrar em uma estrada de terra secundária. No percurso, são encontrados biomas típicos do cerrado e da Amazônia, além de diversos animais silvestres (Figura 5). Aproximadamente a cada cinco quilômetros encontram-se entradas para fazendas e pequenas propriedades rurais. Após $20 \mathrm{~km}$ pedalados o cicloturista passará pela Agrovila Alto Bonito, uma pequena comunidade de agricultores onde vivem aproximadamente cinquenta famílias. No caminho também são encontradas algumas nascentes, córregos e rios, como o Gameleira (um pequeno rio de água potável onde o cicloturista poderá se refrescar). $O$ roteiro também cruza a Ferrovia Norte-Sul e a rodovia estadual TO-226. Chegando a Palmeirante o cicloturista poderá conhecer a Praia das Palmeiras (Figura 6), um dos principais atrativos turísticos do local à beira do Rio Tocantins e pernoitar em uma das pousadas, hotel ou acampar na praia, se preferir. A praia só funcionava durante três meses do ano, mas por causa do projeto de compensação do Consórcio Estreito de Energia (CESTE) ela passou por uma reestruturação e agora é permanente, possuindo barracas onde funcionam bares, lanchonetes e restaurantes, palco para shows e banheiros, inclusive para pessoas com deficiência física e dificuldades de locomoção. O tempo médio desse percurso pedalando a 15 $\mathrm{km} / \mathrm{h}$ é de aproximadamente $7 \mathrm{~h}$, incluindo as paradas. É um roteiro que precisa ter pernoite, pois fica muito cansativo ir e voltar no mesmo dia. 
Carvalho, T.J.L; Ramos, J.L.; Sydow, E.

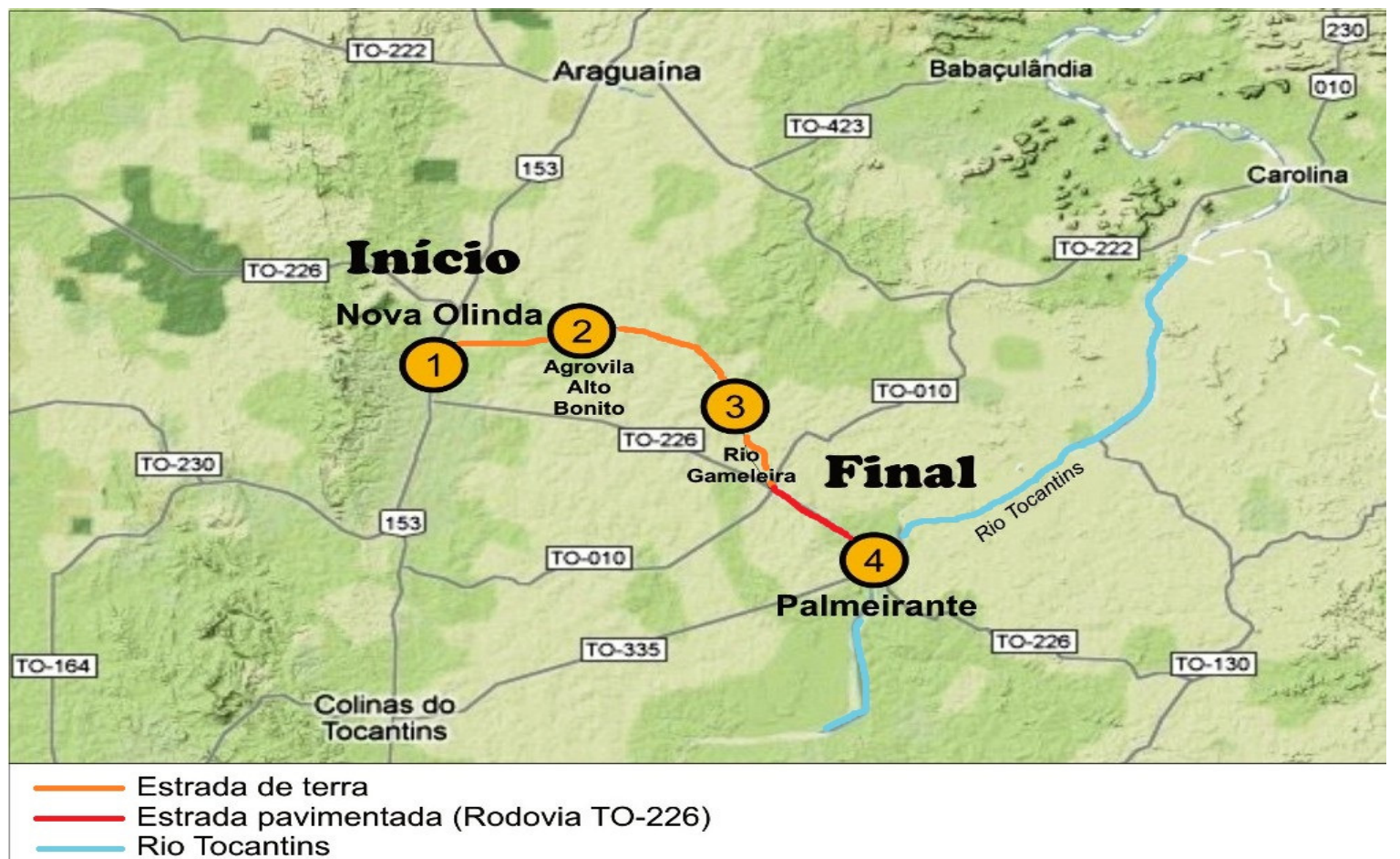

Figura 4: mapa do roteiro Nova Olinda/Palmeirante.

Figure 4: Map of the tour Nova Olinda/Palmirante.

Fonte: Google Mapas (2013). Alterado por Jônatas Ramos.

Source: Google Maps (2013). Modified by Jônatas Ramos.

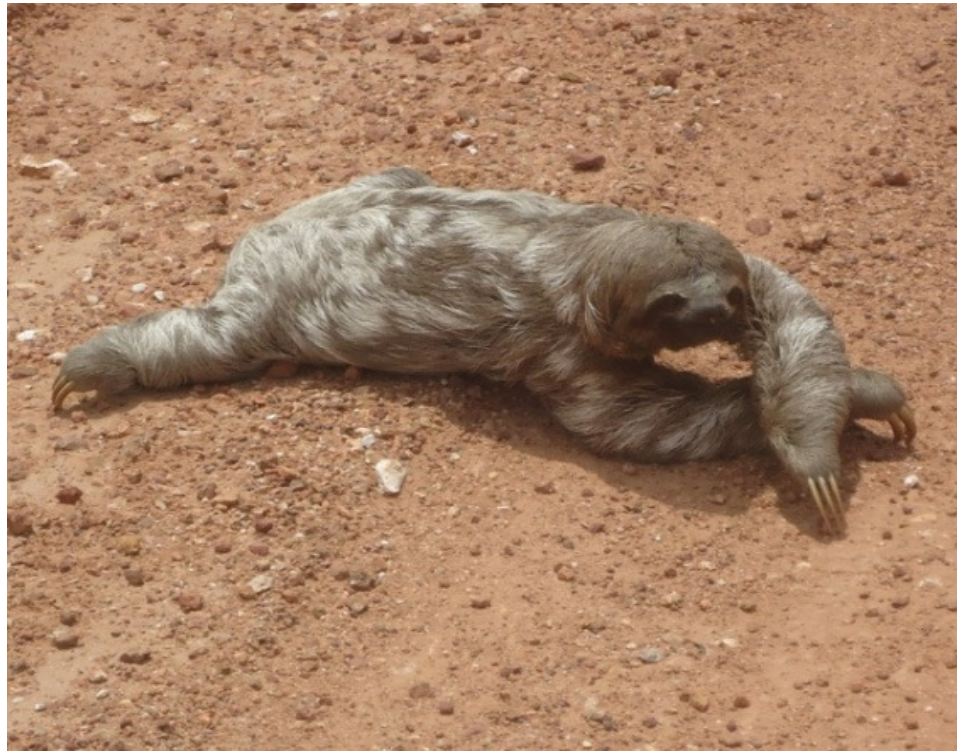

Figura 5: Bicho-preguiça atravessando a estrada na região de Palmeirante.

Figure 5: Sloth crossing the road in the region of Palmeirante.

Foto: Autores (2013). Photo: Authors (2013). 


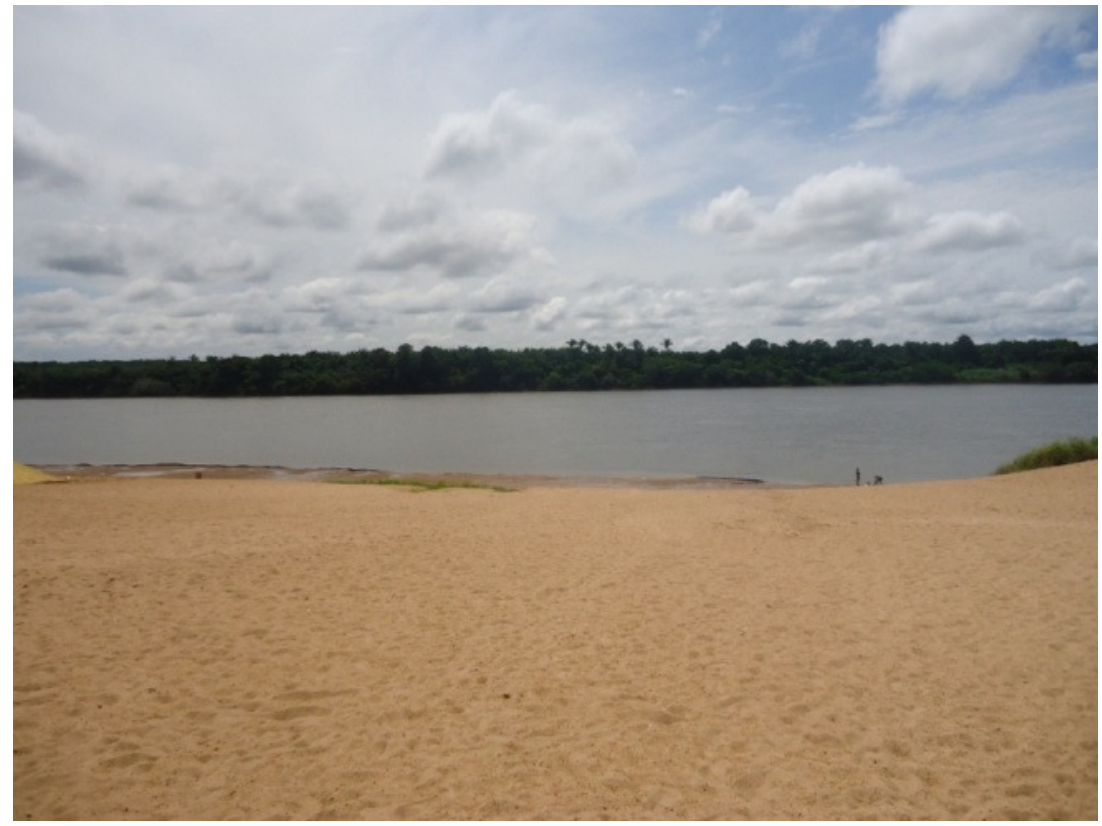

Figura 6: Praia das Palmeiras, no município de Palmeirante.

Figure 6: Palmeiras Beach, in the Palmertante City.

\section{Metodologia}

Foi feita pesquisa em livros, artigos, monografias, manuais, internet e normas técnicas da ABNT, buscando nortear referências sobre assuntos como turismo, ecoturismo e cicloturismo. Neste período foi realizada uma breve pesquisa com alguns participantes de ciclismo da região sobre possíveis roteiros. Após a definição deste, a segunda etapa foi a realização de uma pesquisa de campo com o objetivo específico de analisar a viabilidade de implementação dos roteiros, segurança, características da região, condições gerais da infraestrutura, registro dos atrativos turísticos nos percursos e registro fotográfico. A primeira visita foi realizada dia 10 de fevereiro de 2013 no roteiro que liga Araguaína a Cachoeira do Jenipapo, com $42 \mathrm{~km}$ de extensão. A segunda visita foi realizada no dia $17 \mathrm{de}$ fevereiro de 2013 no percurso que liga o município de Nova Olinda a Palmeirante em uma estrada secundária de $80 \mathrm{~km}$ de extensão. Durante esta pesquisa também foram observados possíveis pontos de apoio para os cicloturistas. Após as visitas, a terceira etapa foi a elaboração de mapas dos roteiros, além de um levantamento teórico sobre características específicas de cada município.

\section{Considerações Finais}

Os resultados da pesquisa bibliográfica demonstram o lado positivo que o cicloturismo pode gerar em uma comunidade. A atividade cicloturística pode gerar empregos, valorizar a herança material e imaterial, conservar o patrimônio histórico e a biodiversidade, aumentar a consciência da população local e dos turistas sobre a necessidade de 
proteção do meio ambiente, além de divulgar a cidade para outros tipos de turistas.

As belezas naturais e encantos característicos encontrados nos roteiros demonstram a potencialidade turística da região para outros segmentos, como o ecoturismo e turismo rural. Os rios, riachos e córregos presentes no percurso podem se desenvolver como atrativos naturais além das cachoeiras, praias e outros pontos já utilizados pela população local. Porém, a infraestrutura das estradas, comércio e empresas ligadas especificamente ao turismo (hotéis, serviços de alimentação e meios de transporte) reforçam a importância do desenvolvimento de projetos para melhoria dessas áreas.

O cicloturismo pode se desenvolver como um novo segmento de mercado na região de Araguaína, divulgando o seu potencial. Ajudando a população e o poder público a compreender o turismo como uma nova fonte econômica, atuando na sua diversificação através da criação de micro e pequenos negócios e operando como instrumento real de melhoria da qualidade de vida.

Sobre os roteiros indicados, é valido destacar os pontos positivos encontrados em ambos, como a qualidade das estradas secundárias, áreas de preservação ambiental, a cultura tradicional e a hospitalidade. Contudo, como em quase todos os destinos turísticos em estágio inicial, diversos problemas podem ser encontrados. Destacam-se como pontos negativos a má conservação dos trechos pavimentados, e a falta de infraestrutura nos destinos finais.

No primeiro percurso, os principais problemas são encontrados na Cachoeira do Jenipapo. Não é possível pernoitar no local, pois falta uma estrutura onde o visitante possa se hospedar e uma área adequada para camping. Outros problemas observados foram a quantidade de banheiros do local que é insuficiente para receber um grande número de pessoas, a trilha interna, que liga a área comunitária até a cachoeira, não possui uma estrutura de segurança, e algumas pontes do trajeto precisam de reparos.

No segundo percurso, o ponto mais crítico é na Rodovia Estadual TO-226 que está mal conservada e cheia de buracos, oferecendo riscos de acidentes, sendo essencial o acompanhamento de veículos de apoio para garantir mais segurança ao cicloturista durante a execução desse roteiro. Outro ponto negativo é a estrutura hoteleira de Palmeirante, que é insuficiente para receber um grande número de hóspedes. A cidade possui um hotel, com 10 leitos e duas pousadas, uma com 7 e outra com 5 leitos.

O desenvolvimento adequado do cicloturismo poderá trazer inúmeras possibilidades, como o fechamento de parcerias com a população rural para atuarem deste o planejamento e até mesmo como ponto de apoio, ofertando serviços ao viajante durante o percurso para ajudar a complementar a renda destas famílias. $\mathrm{O}$ 
primeiro percurso conta com alguns bares e casas de moradores que podem servir como ponto de apoio, já no segundo percurso, a comunidade Agrovila Alto Bonito poderia ofertar refeições para os cicloturistas como forma de geração de renda extra para o local. Também ajudará a combater a sazonalidade, principalmente na praia das Palmeiras, que tem um fluxo turístico significativo apenas no mês de julho (em outras épocas do ano a praia fica praticamente vazia) e a presença de cicloturistas no local poderá desenvolver o turismo na baixa temporada e contribuirá com o aumento da renda da população local e da melhora da infraestrutura da cidade.

O cicloturismo é um modelo ideal de desenvolvimento responsável do turismo, adotado por inúmeros países no mundo, que já defendem a bicicleta como meio de transporte do futuro. É cada vez mais perceptível os benefícios sociais, físicos, econômicos e culturais desse segmento e várias pessoas estão aderindo a esta tendência, o que nos incentiva a desenvolver os respectivos roteiros nas cidades de Araguaína e Nova Olinda.

\section{Referências bibliográficas}

ALEXANDRE, L.M.M. Política de turismo e desenvolvimento local: um binômio necessário. In: BEZERRA, D.M.F. (org.) Planejamento e gestão em turismo. São Paulo: Roca, 2003.

ASSOCIAÇÃO BRASILEIRA DE NORMAS TÉCNICAS. NBR: 15509-1: cicloturismo parte 1: requisitos para produto. Rio de Janeiro, 2007.

ASSOCIAÇÃO DOS CICLOUSUÁRIOS DE FLORIANÓPOLIS - VIACICLO. Circuitos de cicloturismo: manual de incentivo e orientação para os municípios brasileiros. Disponível em:<http://www.clubedecicloturismo.com.br/arquivo/Manual-CircuitosCicloturismo.pdf $>$ Acesso em 20 de dezembro de 2012ás 20:30

BENI, M.C. Análise estrutural do turismo. 10. ed. rev. e amp. São Paulo: Senac, 2004.

BRASIL. Lei no 9.503, de 23 de setembro de 1997. Código de Trânsito Brasileiro, Brasília, DF, 23 set. 1997. Disponível em: <http://www.planalto.gov.br/ccivil 03/leis/ 19503.htm> Acesso em 02 de março de 2013 às 15:30

BRASIL. Ministério do Turismo. Manual Ecoturismo: orientações básicas. Brasília: Ministério do Turismo, 2008.

BRASIL. Ministério do Turismo. Plano Aquarela 2020. Brasília: Ministério do Turismo, 2009.

BUENO, C.; PARDO, F.L.; REIFF, F.; VINHA, V.a .Ecoturismo responsável e seus fundamentos. 1. ed. Rio de Janeiro: Technical Books, 2011. 
CAVALLARI, G. Manual de mountain bike \& cicloturismo. 1. ed. São Paulo: Kalapalo, 2012.

EMPRESA BRASILEIRA DE TURISMO (EMBRATUR). Diretrizes para uma política nacional de ecoturismo. Brasília, 1994.

FONSECA, D.H.Q. Análise do segmento de cicloturismo no Caminho dos Anjos. Belo Horizonte: UFMG, 2009.

IGNARRA, L.R. Fundamentos do turismo. 2. ed. rev. e amp. São Paulo: Pioneira Thomson Learning, 2003.

INSTITUTO BRASILEIRO DE GEOGRAFIA E ESTATÍSTICA - IBGE. Infográficos Cidades Araguaína - TO. Disponível em <http://www.ibge.gov.br/cidadesat/ painel/painel.php?codmun=170210 > Acesso em 25 de março de 2013 ás 13:00.

INSTITUTO BRASILEIRO DE GEOGRAFIA E ESTATÍSTICA - IBGE. Infográficos Cidades Nova Olinda - TO. Disponível em <http://www.ibge.gov.br/cidadesat/ painel/painel.php?codmun=171488> Acesso em 25 de março de 2013 ás 13:15.

INSTITUTO BRASILEIRO DE GEOGRAFIA E ESTATÍSTICA - IBGE. Infográficos Cidades Palmeirante - TO. Disponível em <http://www.ibge.gov.br/cidadesat/ painel/painel. php?codmun=171570\#fontes $>$ Acesso em 25 de março de 2013 ás 13:35.

MEDINA, P.B.J. Avaliação dos impactos da visitação pública no Rio Formoso, Bonito, MS, Brasil: subsídios à gestão ambiental do turismo em áreas rurais. Tese doutorado. Escola de Engenharia de São Carlos, USP, 2007.

MELGAR, E. Fundamentos de planejamento e marketing em turismo. São Paulo: Contexto, 2001.

MENDONÇA, R.; NEIMAN, Z. Ecoturismo no Brasil. São Paulo: Manole, 2005.

NETTO, A.P.; ANSARAH, M.G.R. Segmentação do mercado turístico: estudos, produtos e perspectivas. São Paulo: Manole, 2009.

NEIMAN, Z. Ecoturismo e educação ambiental em unidades de conservação: a importância da experiência dirigida. In: COSTA, N.M.C. (org.), NEIMAN, Z.; COSTA, V.C. Pelas trilhas do ecoturismo. São Paulo: Rima, 2008.

PAUPITZ, A. Perfil do cicloturista brasileiro. 2008. Disponível em <http:// www.clubedecicloturismo.com.br/artigos/080301pesquisa/pesquisa.html> Acesso em 01 de março de 2013 às 19:10

ROLDAN, T.R.R. Cicloturismo: planejamento e treinamento. Campinas: UNICAMP, 2000. 
Thiago Junior Lima Carvalho: Universidade Federal do Tocantins, Araguaína, TO, Brasil.

Email: tiagojr7@hotmail.com

Link Currículo Lattes: http://lattes.cnpq.br/8917253895099650

Jônatas Leite Ramos: Universidade Federal do Tocantins, Araguaína, TO, Brasil.

Email: jonatas_Ir@hotmail.com

Link para o currículo Lattes: http://lattes.cnpq.br/1399623801767170

Elisabeth Sydow: Universidade Federal do Tocantins, Araguaína, TO, Brasil.

Email: elisabeth@uft.edu.br

Link para o currículo Lattes: http://lattes.cnpq.br/6435264980379189

Data de submissão: 28 de junho de 2013

Data de recebimento de correções: 28 de junho de 2013

Data do aceite: 01 de setembro de 2013

Avaliado anonimamente 